\title{
Medical termination for pregnancy in early first trimester ( $\leq 63$ days) using combination of mifepristone and misoprostol or misoprostol alone: a systematic review
}

\author{
Ferid A. Abubeker ${ }^{1 *}$ (D, Antonella Lavelanet ${ }^{1}$, Maria I. Rodriguez ${ }^{2}$ and Caron Kim ${ }^{1}$
}

\begin{abstract}
Background: A wide range of drugs have been studied for first trimester medical abortion. Studies evaluating different regimens, including combination mifepristone and misoprostol and misoprostol alone regimens, show varying results related to safety, efficacy and other outcomes. Thus, the objectives of this systematic review were to compare the safety, effectiveness and acceptability of medical abortion and to compare medical with surgical methods of abortion $\leq 63$ days of gestation.

Methods: Pubmed and EMBASE were systematically searched from database inception through January 2019 using a combination of MeSH, keywords and text words.

Randomized controlled trials on induced abortion at $\leq 63$ days that compared different regimens of medical abortion using mifepristone and/or misoprostol and trials that compared medical with surgical methods of abortion were included.

We extracted data into a pre-designed form, calculated effect estimates, and performed meta-analyses where possible. The primary outcomes were ongoing pregnancy and successful abortion.

Results: Thirty-three studies composed of 22,275 participants were included in this review. Combined regimens using mifepristone and misoprostol had lower rates of ongoing pregnancy, higher rates of successful abortion and satisfaction compared to misoprostol only regimens. In combined regimens, misoprostol $800 \mu \mathrm{g}$ was more effective than $400 \mu \mathrm{g}$. There was no significant difference in dosing intervals between mifepristone and misoprostol and routes of misoprostol administration in combination or misoprostol alone regimens. The rate of serious adverse events was generally low.

(Continued on next page)
\end{abstract}

\footnotetext{
* Correspondence: ferid.abas@sphmmc.edu.et

'UNDP/UNFPA/UNICEF/WHO/World Bank Special Programme of Research, Development and Research Training in Human Reproduction (HRP),

Department of Reproductive Health and Research, World Health Organization, Geneva, Switzerland

Full list of author information is available at the end of the article
}

(c) The Author(s). 2020 Open Access This article is licensed under a Creative Commons Attribution 4.0 International License, which permits use, sharing, adaptation, distribution and reproduction in any medium or format, as long as you give appropriate credit to the original author(s) and the source, provide a link to the Creative Commons licence, and indicate if changes were made. The images or other third party material in this article are included in the article's Creative Commons licence, unless indicated otherwise in a credit line to the material. If material is not included in the article's Creative Commons licence and your intended use is not permitted by statutory regulation or exceeds the permitted use, you will need to obtain permission directly from the copyright holder. To view a copy of this licence, visit http://creativecommons.org/licenses/by/4.0/ The Creative Commons Public Domain Dedication waiver (http://creativecommons.org/publicdomain/zero/1.0/) applies to the data made available in this article, unless otherwise stated in a credit line to the data. 
(Continued from previous page)

Conclusion: In this systematic review, we find that medical methods of abortion utilizing combination mifepristone and misoprostol or misoprostol alone are effective, safe and acceptable. More robust studies evaluating both the different combination and misoprostol alone regimens are needed to strengthen existing evidence as well as assess patient perspectives towards a particular regimen.

Keywords: Medical abortion, First trimester, Mifepristone, Misoprostol, Systematic review

\section{Background}

Medical methods emerged as an alternative to surgical abortion with the discovery of prostaglandins in the early 1970s [1-3]. Their use has evolved in the last two decades and various drugs have been used for first trimester medical abortion. Several studies have explored utilization of mifepristone, methotrexate and various prostaglandins with different doses, routes and intervals of administration [4]. A Cochrane review compared different medical methods for first trimester abortion in 2011 and since that time, there has been growing evidence assessing the effectiveness and safety of medical methods using two specific regimens: the combination regimen (mifepristone and misoprostol) and misoprostol alone [5].

However, individual studies evaluating medical management of abortion at $\leq 63$ days have not demonstrated superiority of one of these regimens. Not only have studies compared combination of mifepristone and misoprostol (combination mifepristone misoprostol) with misoprostol alone [6-8], other studies have looked at different routes and doses of misoprostol in combined regimens $[9,10]$, besides comparing different intervals between mifepristone and misoprostol doses [11-13]. Similarly, different misoprostol only regimens have been evaluated [14].

The 2012 World Health Organization (WHO) safe abortion guideline had varying regimens for induced abortion at $<12$ weeks. With the emergence of new evidence, this systematic review was done as part of the evidence synthesis for the WHO guidance on medical abortion. Options for medical abortion vary globally, and evidence-based guidance is needed to inform clinical care in selecting a regimen. The objectives of this review were to compare the effectiveness, safety and acceptability of different regimens of medical abortion containing mifepristone and/or misoprostol and to compare medical with surgical methods of abortion at $\leq 63$ days of gestational age.

\section{Methods}

\section{Search strategy}

We searched Pubmed and EMBASE for randomized controlled trials on induced abortion at $\leq 63$ days. Our search was from database inception through January
2019 using a combination of $\mathrm{MeSH}$, keywords and text words (Additional file 1).

\section{Selection criteria}

Inclusion criteria comprised randomized controlled trials (RCTs) that compared different medication regimens for induced abortion at $\leq 63$ days using mifepristone and/or misoprostol; different frequencies of administration of misoprostol in combination regimens; different doses and dosing intervals of misoprostol in combination regimens; different routes of misoprostol in combination regimens; and different dosing regimens and routes in misoprostol only regimens. We also included trials that compared surgical and medical abortion using combination or misoprostol alone regimens. We excluded studies that included induced abortion > 63 days, missed abortion, miscarriage, fetal demise and those that did not report on the primary outcomes. We also excluded studies comparing medical regimens beyond mifepristone and/or misoprostol, such as those using methotrexate or gemeprost. In addition, we excluded studies that compared various mifepristone dosages beyond the WHO recommended $200 \mathrm{mg}$ dose, as a previously conducted Cochrane review showed effectiveness of mifepristone at this lower dose (5).

All search results (titles, abstracts and when necessary, full articles) were screened using the Covidence tool [15].

\section{Data extraction and analysis}

Data extraction was performed using a standardized data-abstraction form.

The primary outcomes were ongoing pregnancy and successful abortion (defined as uterine evacuation without need for surgical intervention). Secondary outcomes were: safety (defined as serious adverse events and complications; such as hospitalization; blood transfusion; need for surgical interventions beyond uterine evacuation; or death), expulsion time from initiation of treatment, side effects (including bleeding; pain; and vomiting) and satisfaction.

For dichotomous data (e.g., complete abortion rate), we used the number of events in the control and intervention groups of each study to calculate Risk Ratios (RRs) with 95\% confidence intervals for our primary 
outcome, and secondary outcomes as available. Analyses were conducted using RevMan version 5.3 (Copenhagen, Denmark: The Nordic Cochrane Centre, The Cochrane Collaboration, 2014).

We used GRADEpro software and Cochrane methods to evaluate the overall quality of the body of evidence for the main review outcomes. We relied on GRADE (Grading of Recommendations, Assessment, Development and Evaluations) criteria (e.g., risk of bias, consistency of effect, imprecision, indirectness, and publication bias) to assess the quality of the evidence. The Cochrane Risk of Bias Assessment tool was used to assess risk of bias across studies [16]. We specifically assessed: selection (random sequence generation and allocation concealment); performance (blinding of participants and personnel); detection (blinding of outcome assessors); attrition (incomplete outcome data); reporting (selective reporting); and other biases. Studies were ranked as low risk, high risk, or unclear risk using the criteria outlined by the Cochrane Handbook for Systematic Reviews of Interventions [16].

Two review authors (FAA and CK) independently performed study selection, data extraction, assessment of risk of bias and quality of evidence. Discrepancies were resolved by discussion with the third author (MIR).

\section{Results}

The initial search yielded 1506 articles, of which 33 articles fit our inclusion criteria (Fig. 1). Studies included for this review were conducted across 19 countries with a total of 22,275 participants. Using the World Bank's 2018 classification of economies, the articles represent data from six high income economies, six upper-middle income economies, six lower-middle income economies and one low income economy [17]. The year of publication ranged from 1994 to 2017. The characteristics of the included studies are shown in Table 1 . Approximately $85 \%$ of the included studies had a low risk of selection bias based on random sequence generation and $78 \%$ had a high risk of performance bias (Additional file 2).

\section{Medical regimens}

Different regimens of medical abortion management containing combination mifepristone misoprostol, or misoprostol alone were reviewed. Six studies compared

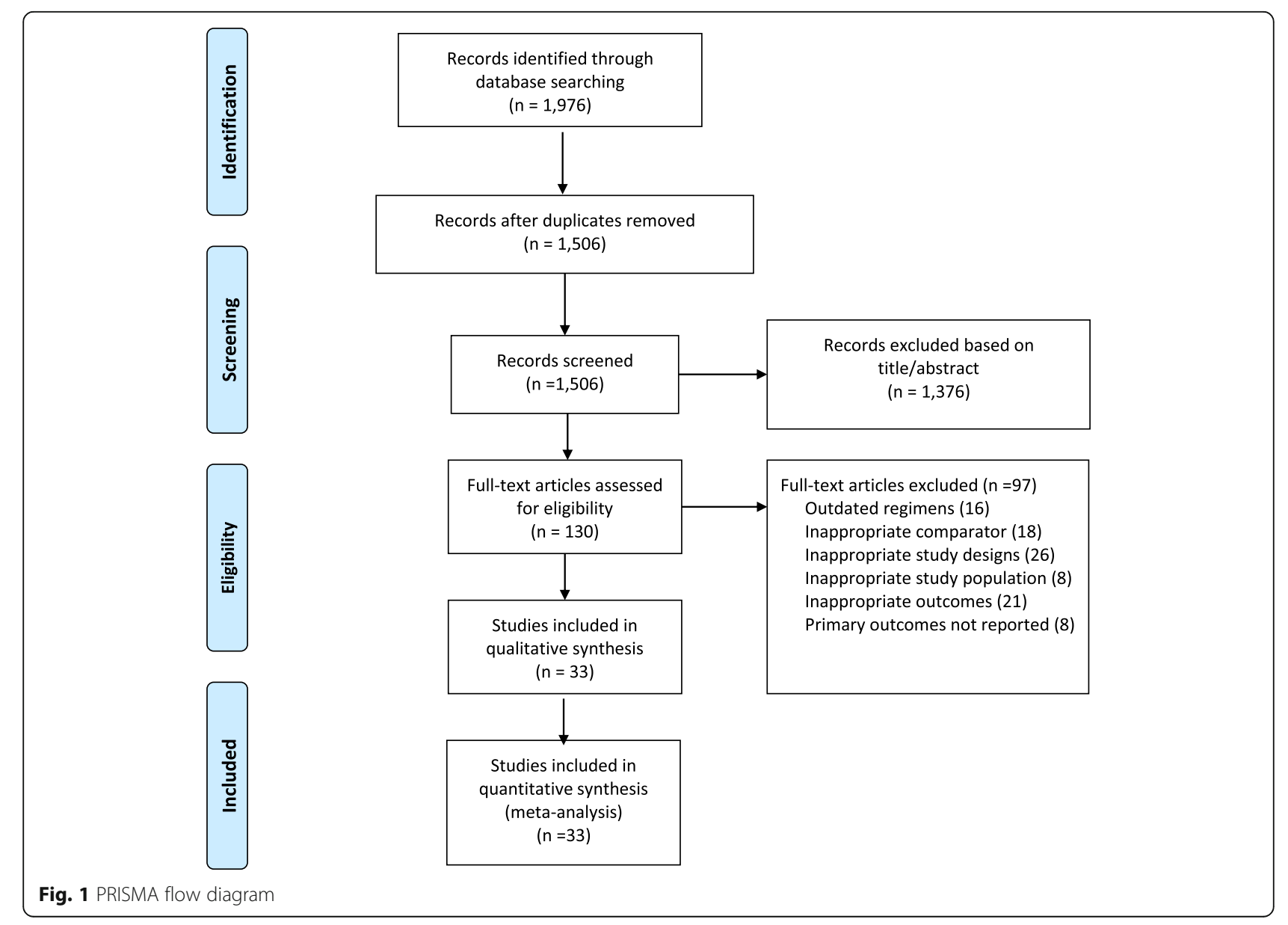




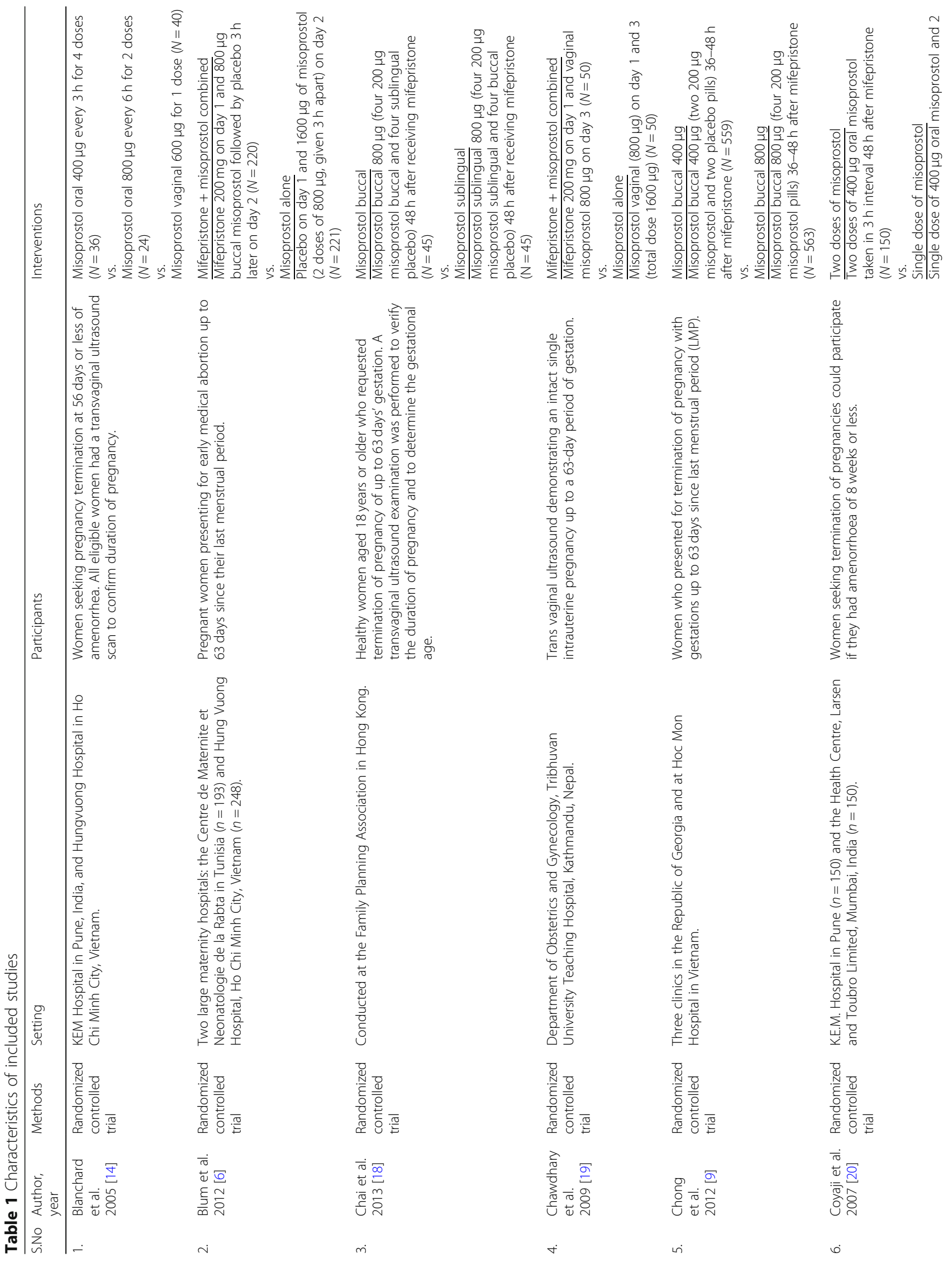




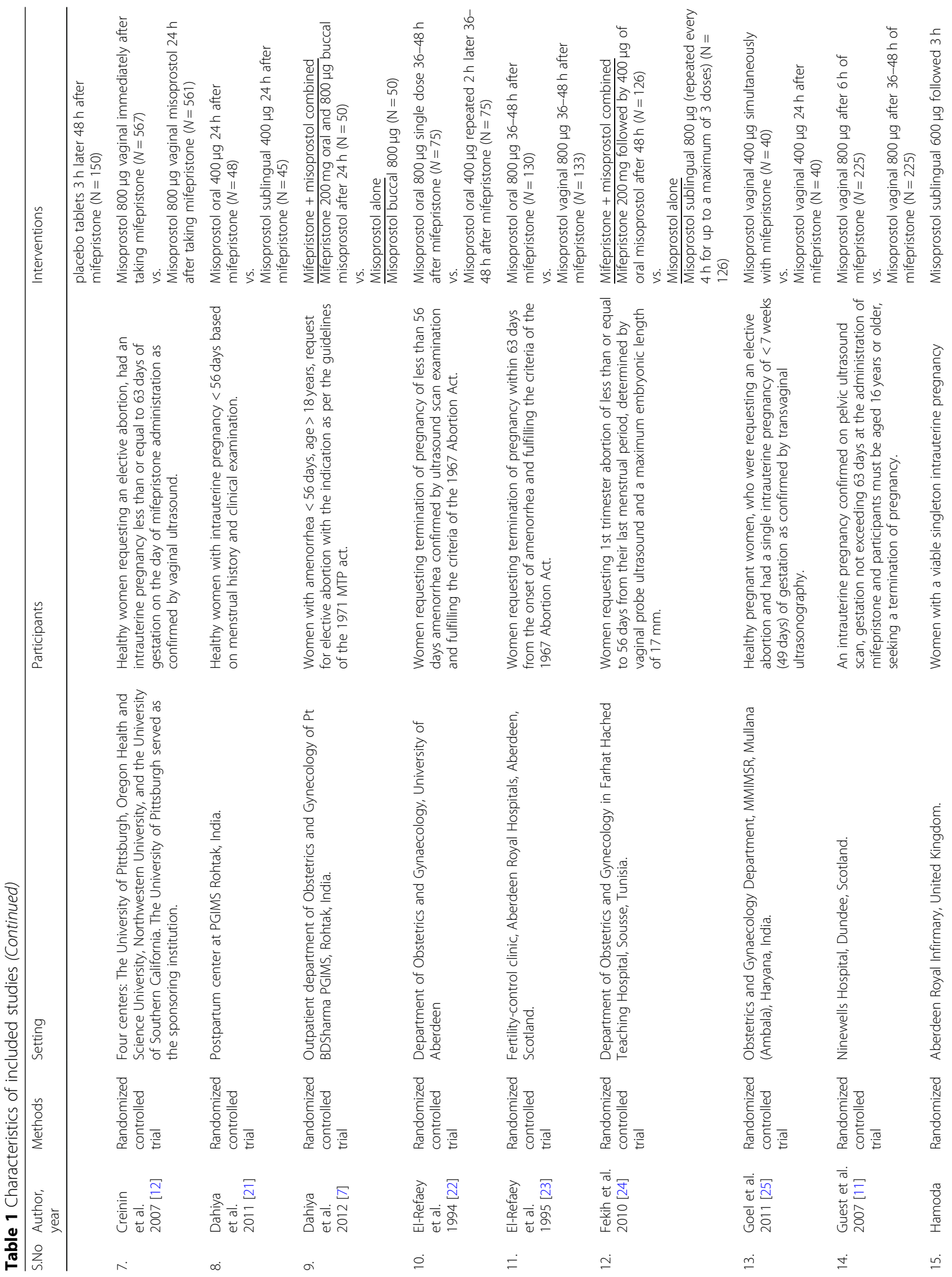




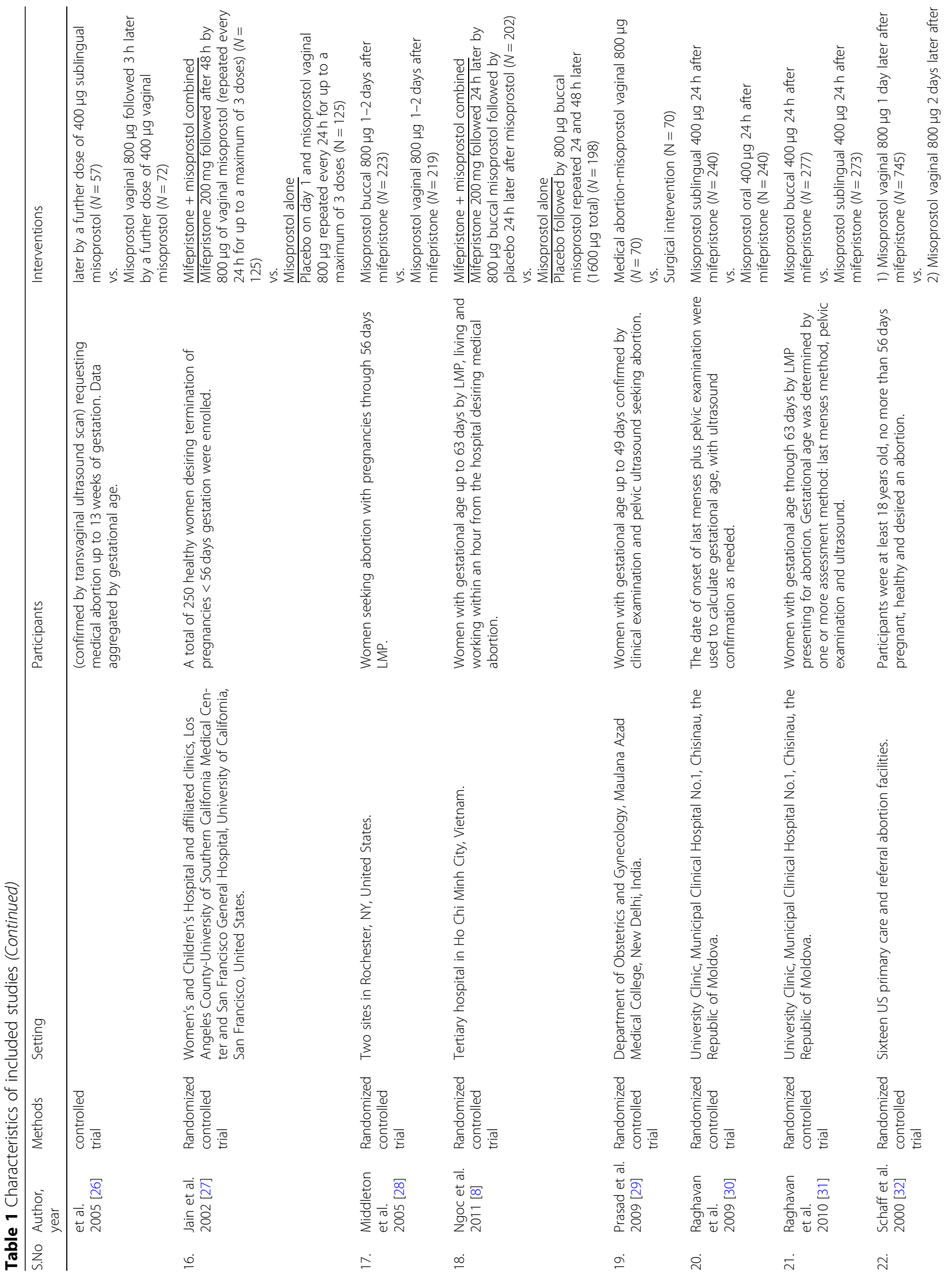




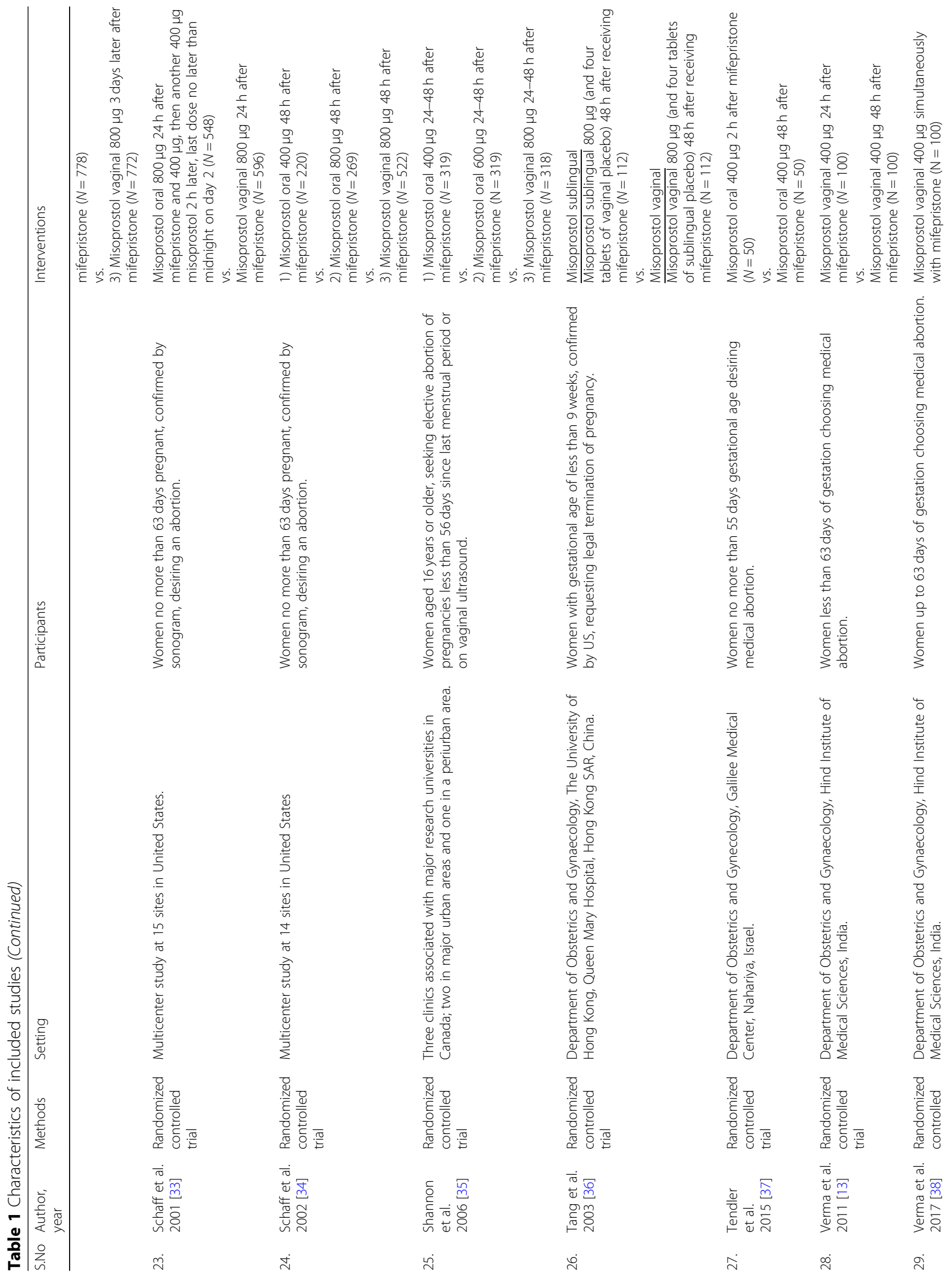




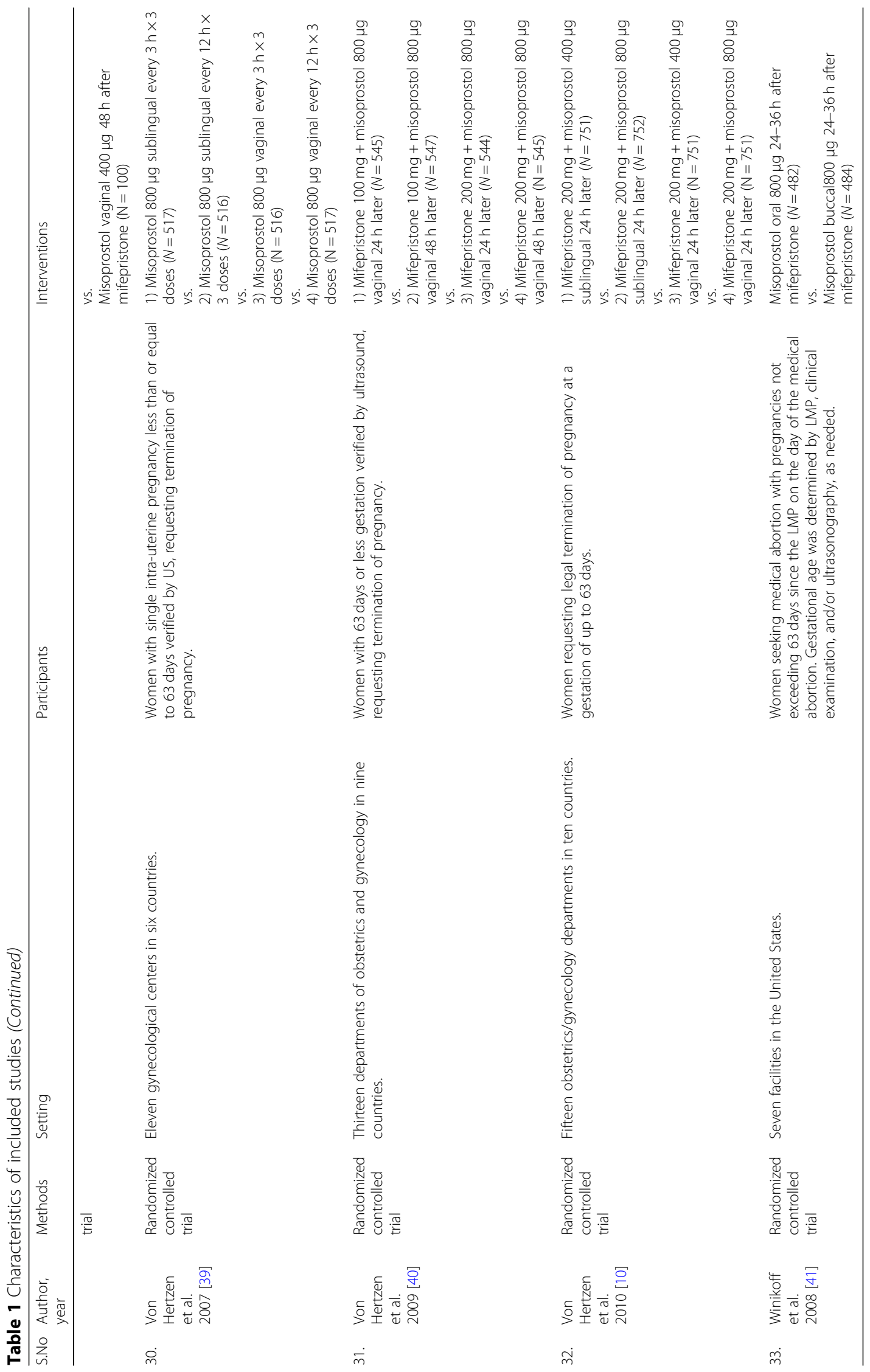


combined mifepristone misoprostol vs. misoprostol alone, 6 studies compared different doses of misoprostol in combined regimens, 8 studies compared the timing interval between mifepristone and misoprostol in combined regimens, 13 compared routes of misoprostol in combined regimens, 2 compared various misoprostol alone regimens, and 1 study compared medical with suction evacuation.

\section{Combination mifepristone misoprostol compared with misoprostol alone}

Three studies compared combined with misoprostol alone regimens [6-8] (Table 2).

Women treated with a combined regimen had lower rates of ongoing pregnancy (RR 0.16 CI 95\% 0.08-0.31, low certainty of evidence) and higher rates of successful abortion (RR 1.23 CI 95\% 1.16-1.30, very low certainty of evidence) compared to women treated with a misoprostol only regimen. The combined regimen resulted in a higher rate of satisfaction compared with misoprostol only regimen (RR 1.13 CI 95\% 1.00-1.26, low certainty of evidence) (Table S1, Additional file 3).

2. Comparisons of different regimens of misoprostol when combined with mifepristone

\subsection{Comparison of misoprostol doses in combined regimen}

Six studies assessed different doses of misoprostol, using the same routes, in combined regimens. These included comparisons of $400 \mu \mathrm{g}$ buccal vs. $800 \mu \mathrm{g}$ buccal [9], $400 \mu \mathrm{g}$ oral twice vs. $400 \mu \mathrm{g}$ oral once [20], $800 \mu \mathrm{g}$ oral once vs. $400 \mu \mathrm{g}$ oral twice [22, 34], $400 \mu \mathrm{g}$ sublingual vs. $800 \mu \mathrm{g}$ sublingual [10], $400 \mu \mathrm{g}$ vaginal vs. $800 \mu \mathrm{g}$ vaginal [10] and $400 \mu \mathrm{g}$ oral versus $600 \mu \mathrm{g}$ oral [35] (Table 2).

Women treated with misoprostol $400 \mu \mathrm{g}$ buccal had lower rates of ongoing pregnancy (RR 0.16 CI 95\% 0.08-0.31, moderate certainty of evidence) and higher rates of successful abortion (RR 1.23 CI 95\% 1.16-1.30, moderate certainty of evidence) compared to women taking $800 \mu \mathrm{g}$ buccal [9].

For women taking a total of $800 \mu \mathrm{g}$ oral misoprostol, there were lower rates of ongoing pregnancy (RR $0.10 \mathrm{CI}$ $95 \%$ 0.01-0.80, low certainty of evidence) compared to women taking oral $400 \mu \mathrm{g}$ [20]. Other studies that investigated $800 \mu \mathrm{g}$ dosage of misoprostol showed comparable rates of successful abortion between $800 \mu \mathrm{g}$ oral once and $400 \mu \mathrm{g}$ oral twice (RR 0.94 CI 95\% 0.89-0.99, moderate certainty of evidence) [22, 34].

Another significant finding was that women taking $400 \mu \mathrm{g}$ sublingual misoprostol were more likely to experience ongoing pregnancy compared to the group who took $800 \mu \mathrm{g}$ misoprostol (RR 3.44 CI 95\% 1.14-10.40, moderate certainty of evidence) [10].
Although the remaining comparisons did not provide statistically significant findings, there was moderate certainty on the higher rates of ongoing pregnancy in the $400 \mu \mathrm{g}$ vaginal misoprostol compared to the $800 \mu \mathrm{g}$ vaginal misoprostol (Table 2). Safety and satisfaction appeared to be comparable throughout the groups (Table S2, Additional file 3).

\subsection{Comparison of dosing intervals between mifepristone and misoprostol in combined regimen}

Eight studies assessed different time intervals between mifepristone and misoprostol dosing in the combined regimen. These include comparisons between $<8 \mathrm{~h}$ vs. $>$ $24 \mathrm{~h}[11,12], 24 \mathrm{~h}$ vs. $48 \mathrm{~h}[13,32,40]$, concurrent administration vs. $24 \mathrm{~h}[25,38]$ and $<8 \mathrm{~h}$ vs. $48 \mathrm{~h}$ [37] (Table 2).

Administration of misoprostol within $8 \mathrm{~h}$ of mifepristone was found to have similar rates of successful abortion compared to 24-h (RR 0.98 CI 95\% 0.91-1.06, moderate certainty of evidence) and 48-h intervals (RR 0.91 CI 95\% $0.66-1.25$, very low certainty of evidence) $[11,12,37]$.

There may be little to no difference in rates of successful abortion between concurrent administration of misoprostol and a 24-h interval (RR 1.01 CI 95\% 0.84-1.21, very low certainty of evidence) $[25,38]$. There was no significant difference between $24-\mathrm{h}$ and 48 -h interval in terms of ongoing pregnancy and successful abortion [13, 32, 40]. All dosing interval comparisons showed similar safety and satisfaction rates (Table S3, Additional file 3).

\section{Comparisons of misoprostol routes in combined mifepristone misoprostol regimen}

Thirteen studies assessed different routes of misoprostol in the combined regimen (Table 2).

Treatment with $800 \mu \mathrm{g}$ oral misoprostol showed higher rates of ongoing pregnancy compared with vaginal (RR 6.70 CI 95\% 1.88-23.86, moderate certainty of evidence) and buccal routes (RR 3.61 CI 95\% 1.20-10.80, low certainty of evidence) [23, 33, 34, 41].

Women treated through sublingual route were found to have similar rates of successful abortion compared to those treated through vaginal route (RR 0.99 CI 95\% 0.92-1.07, moderate certainty of evidence) [10].

There may be little to no difference in successful abortion rates among women treated through buccal route compared to those treated through sublingual (RR $0.98 \mathrm{CI}$ $95 \% 0.73-1.33$, very low certainty of evidence) or vaginal routes (RR 1.00 CI 95\% $0.87-1.15$, low certainty of evidence) $[18,28]$.

Safety and satisfaction rates of tested routes appears to be similar (Table S4, Additional file 3). 


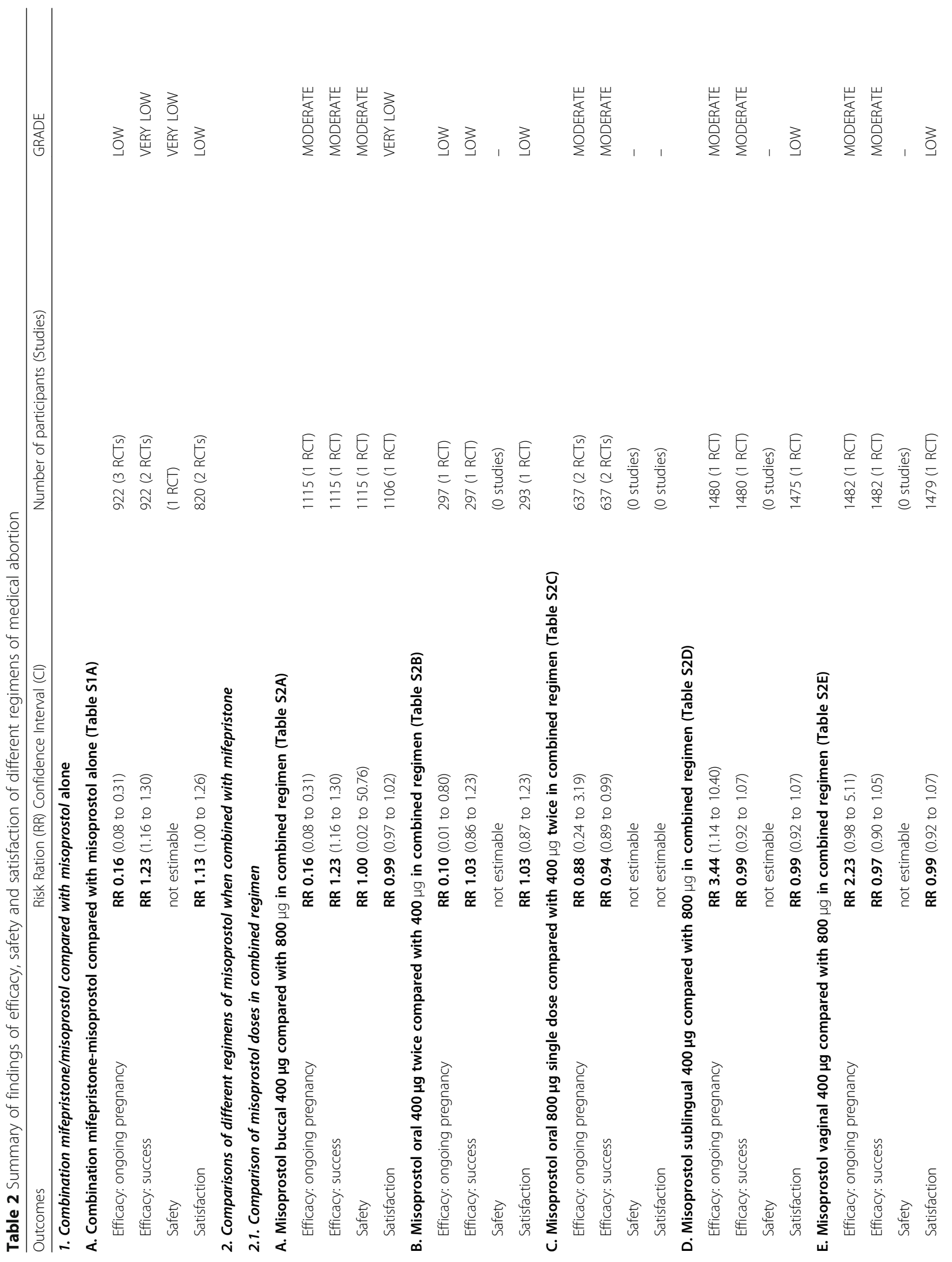




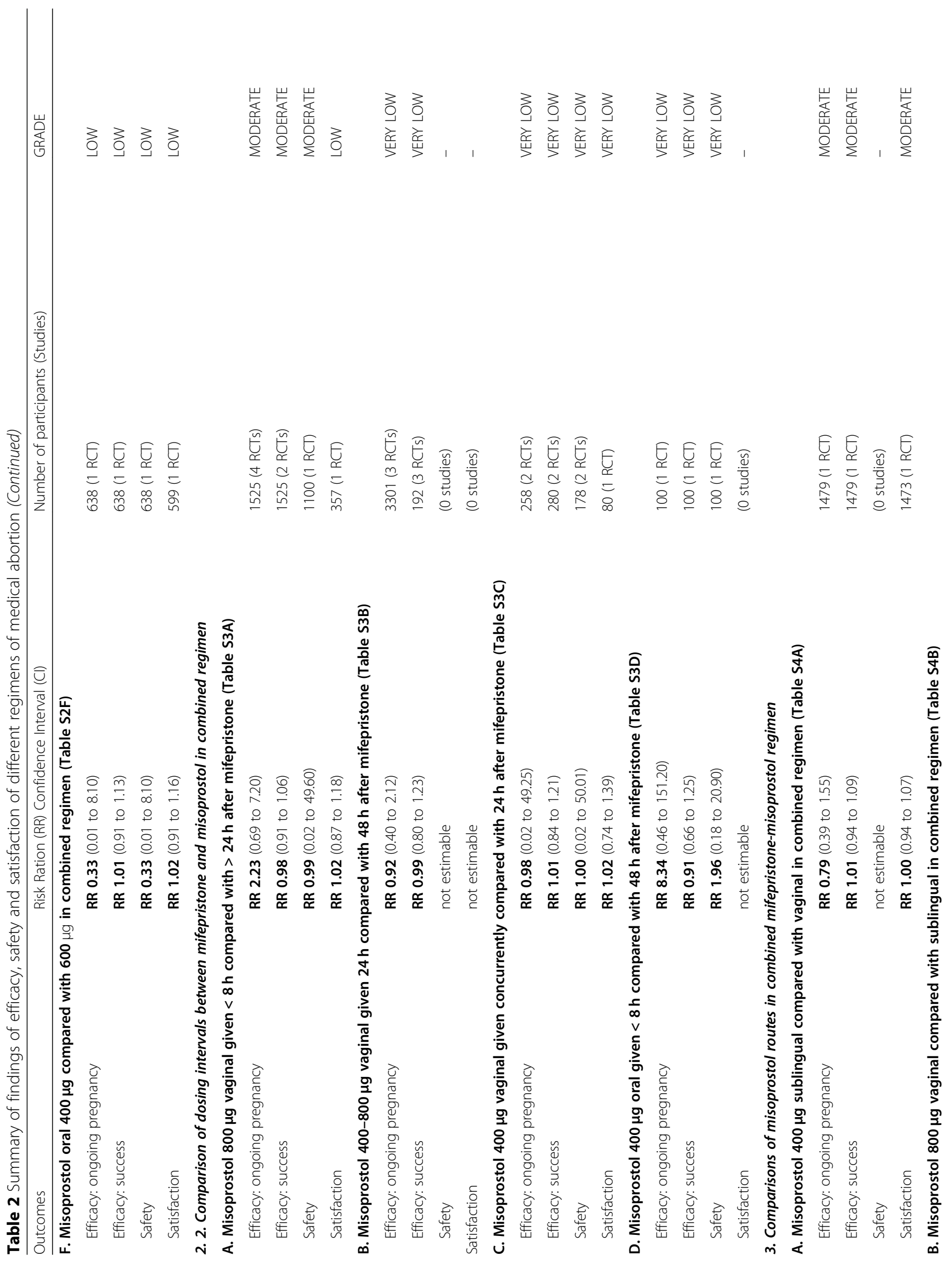




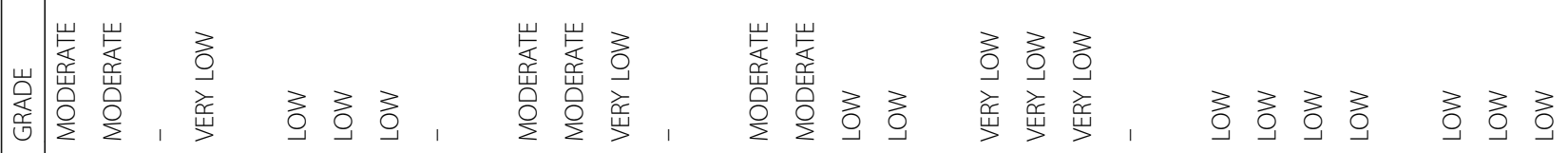

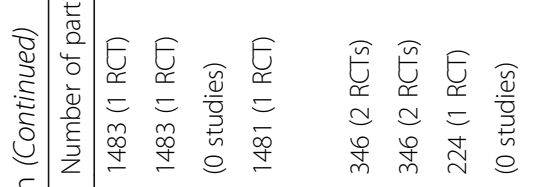

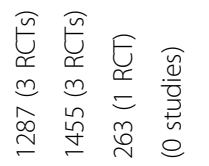

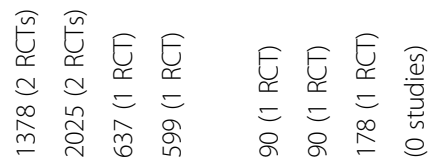

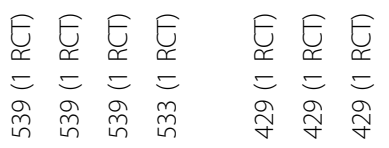
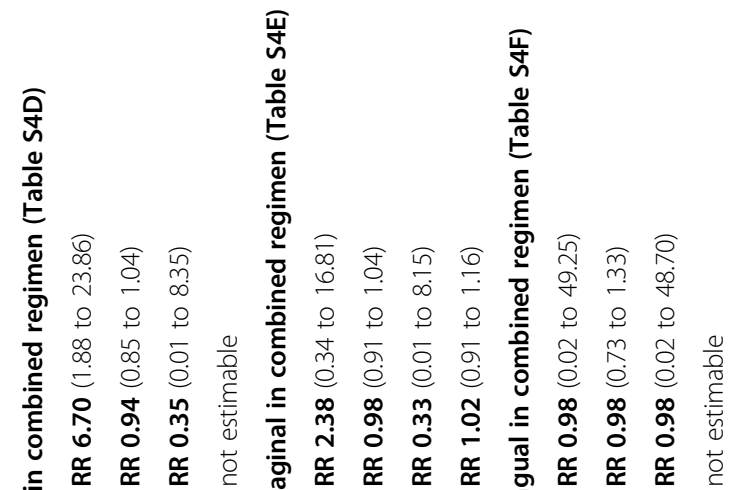

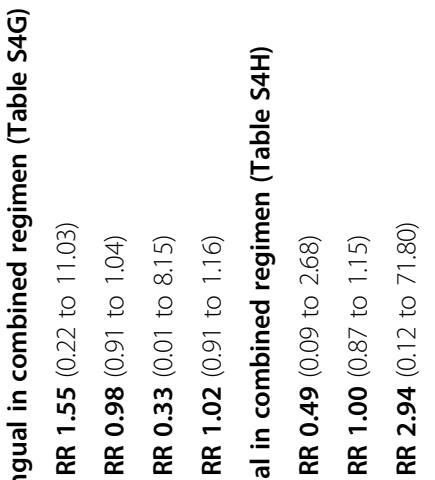

듬

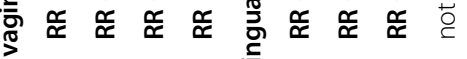
웅

응 ज 


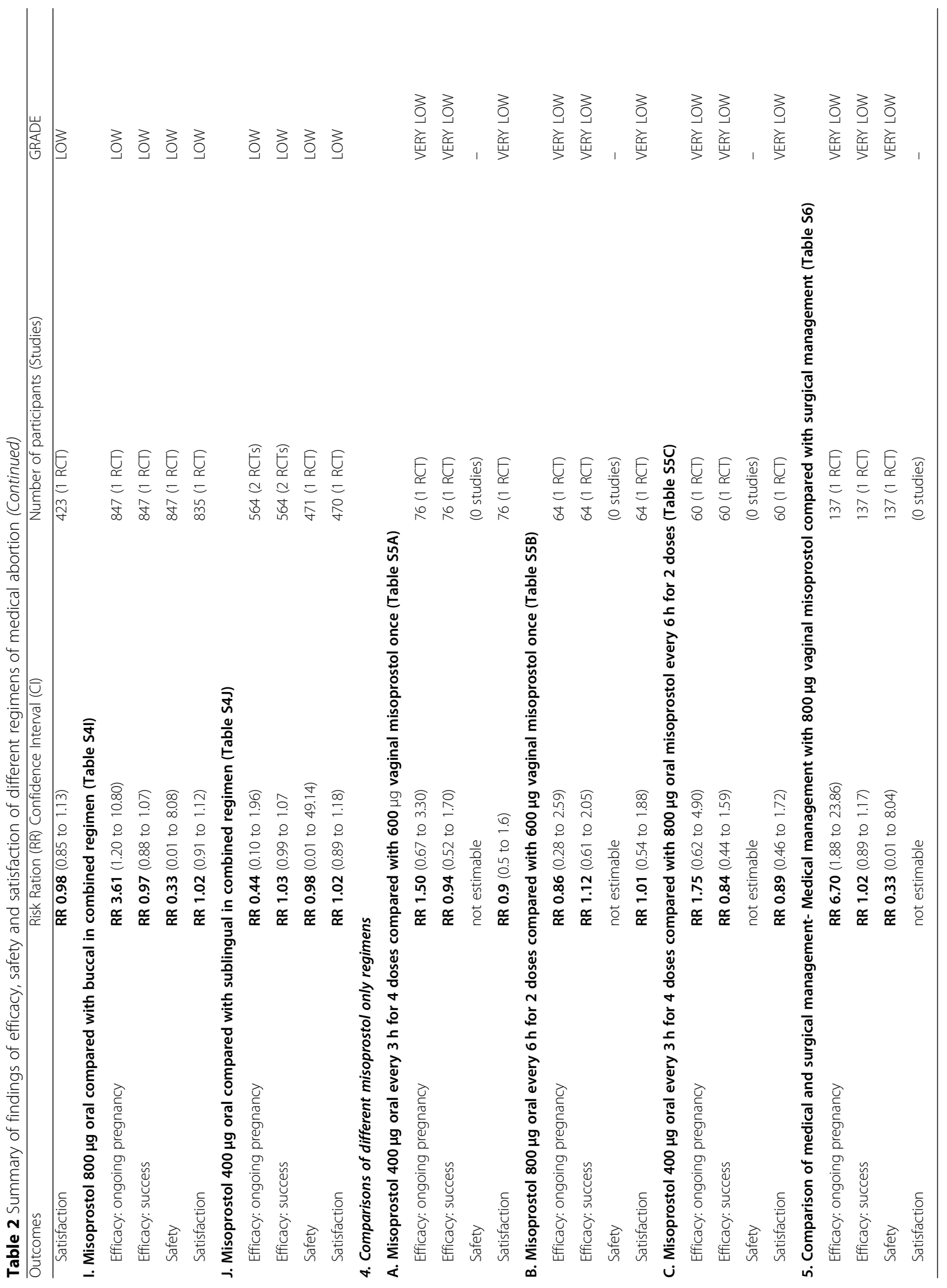




\section{Comparisons of different misoprostol only regimens}

One study compared 7 different misoprostol only regimens [14] (Table 2). In this study, oral misoprostol $400 \mu \mathrm{g}$ every $3 \mathrm{~h}$ administered for 4 doses was compared to vaginal misoprostol $600 \mu \mathrm{g}$ once and oral misoprostol $800 \mu \mathrm{g}$ administered every $6 \mathrm{~h}$ for 2 doses. In another arm, vaginal misoprostol $600 \mu \mathrm{g}$ once was compared to oral misoprostol $800 \mu \mathrm{g}$ administered every $6 \mathrm{~h}$ for 2 doses.

None of the study arms was more effective than the other. In addition, we were not able to compare the safety outcomes of these regimens (Table S5, Additional file 3 ).

\section{Comparisons of medical versus surgical management}

One study compared surgical with medical management using a single dose of $800 \mu \mathrm{g}$ vaginal misoprostol [29] (Table 2). Women treated with medical method showed higher rates of ongoing pregnancy than those receiving surgical management (RR 6.70 CI 95\% 1.8823.8). There was little to no difference in rates of successful abortion between the two methods (RR $1.02 \mathrm{CI}$ $95 \%$ 0.89-1.17). There was a lower rate of serious adverse events and complications among women who received medical compared with those who received surgical management (RR 0.33 CI 95\% 0.01-8.04). The certainty of evidence is very low for all reported outcomes (Table S6, Additional file 3).

\section{Discussion}

In this review we identified 33 trials conducted across different settings with a total of 22,275 participants. We compared effectiveness, safety and acceptability of different combination and misoprostol only regimens. Acceptability was not explicitly reported; thus, we used satisfaction, which was reported in 25 of the included studies, as a proxy indicator.

The results of this review demonstrate that the majority of the studies compared different combination and misoprostol alone regimens in terms of dosing, route and frequency of administration. This reflects the fact that mifepristone has replaced older medications, such as methotrexate and gemeprost, when used in combination with misoprostol.

A combined regimen of mifepristone and misoprostol was found to be more effective in terms of lower rates of ongoing pregnancy and higher rates of successful abortion compared to the misoprostol alone regimen [6-8].

There have been multiple studies that focus on the combination regimen, comparing various misoprostol doses and routes and the interval between mifepristone and misoprostol.

When comparing different doses of misoprostol in the combined mifepristone misoprostol regimen, the included studies focused on the dosages of $400 \mu \mathrm{g}$ and $800 \mu \mathrm{g}$. Comparing $400 \mu \mathrm{g}$ to $800 \mu \mathrm{g}$ buccal misoprostol [9], treatment with $400 \mu \mathrm{g}$ misoprostol was found to be more effective (moderate certainty of evidence). On the other hand, administration of $800 \mu \mathrm{g}$ oral misoprostol demonstrated more effectiveness than $400 \mu \mathrm{g}$ oral misoprostol. Moreover, there is moderate certainty of evidence that $800 \mu \mathrm{g}$ sublingual misoprostol is 3 times more effective than $400 \mu \mathrm{g}$ [10]. Although there were multiple comparisons, it appears that the dosage of $800 \mu \mathrm{g}$ of misoprostol in the combined mifepristone misoprostol regimen showed higher effectiveness with lower rates of ongoing pregnancy and higher rates of successful abortion. In addition, $800 \mu$ g were associated with higher rates of satisfaction $[9,10]$.

Review of studies that compared different dosing interval between mifepristone and misoprostol in combined regimen showed inconclusive results. Individual studies showed a 24-h interval to be more effective compared to either 8- or 48-h intervals [5, 9, 10, 32, 40]. However, we were not able to replicate these findings in the pooled analysis. We found similar rates of effectiveness between 24-h and 48-h intervals. In addition, the safety profile and satisfaction rates were not significantly different across intervals.

Comparing 8-h interval to 24-h and 48-h intervals showed that a shorter interval of misoprostol administration did not significantly compromise effectiveness [11, 12]. Furthermore, a 24-h interval was no more effective than concurrent administration. Our results align with existing evidence that demonstrates that concurrent administration can lead to higher satisfaction rates $[5,25$, 38], while also impacting the number of visits required and time needed to complete the procedure [5]. Nonetheless, satisfaction rate was not consistently reported across studies. Thus, further research is needed to assess the impact of dosing interval on this outcome and how it relates to the acceptability of the procedure to women.

When comparing studies to determine optimal routes of misoprostol in combined mifepristone misoprostol regimen, there were mixed results. There is moderate certainty of evidence that oral misoprostol is significantly less effective than vaginal misoprostol $[23,33,34]$. Similarly, oral route was less effective than buccal route (low certainty of evidence) [41]. However, individual studies show that oral administration of misoprostol in the combined regimen leads to better overall satisfaction $[18,23,33,34]$.

Buccal route was as effective as sublingual and vaginal route and there was no significant difference between 
sublingual and vaginal routes [18, 28, 31]. Given the findings of the non-significant differences between the routes, women should be given the full range options factoring in their satisfaction towards a particular treatment regimen.

A review of one study with 7 different arms comparing misoprostol only regimens failed to demonstrate superiority of one regimen over the others. This potentially means that the compared regimens are equally effective and at this time no conclusions can be made without additional studies evaluating misoprostol only regimens. This is important in order to address the needs of those who cannot afford or access mifepristone [14].

Compared to surgical method, medical management had significantly higher rates of ongoing pregnancy. Lower rates of serious adverse events and complications were observed with medical compared to surgical methods [29]. However, interpretation of this finding requires caution as it was based on only one trial and certainty of evidence was very low.

One study comparing oral versus vaginal misoprostol reported one woman in the vaginal arm who died from a systemic Clostridium sordellii infection [35]. However, in general, the rates of serious adverse events reported in our review are very low, thus we cannot draw definitive conclusions related to adverse events.

\section{Strengths and limitations}

This review has several strengths. We used a comprehensive and replicable search strategy to identify relevant articles. In addition, the included studies were conducted across different settings. We employed the GRADE system that can assist health care providers, program managers and policy makers to design and implement best practice recommendations and guidelines.

Limitations of this review include the inclusion of only RCTs and using satisfaction as a proxy for acceptability. Specifically, inclusion of observational studies could be more informative about client satisfaction and acceptability of treatment regimens. We were not able to demonstrate statistically significant differences for various dosing intervals and routes of misoprostol administration in combination or in misoprostol alone regimens. There are only a limited number of studies for some of the comparisons (medical vs. surgical, misoprostol only regimens). In addition, some of the included studies have a high risk of performance and detection bias. Thus, we recommend future research studies to consider blinding of outcome assessor as it is feasible to blind the individual who is assessing the success of the abortion (whether by history, physical exam or ultrasound) and this in turn can improve the quality of data.

\section{Conclusion}

In this systematic review, we establish that medical methods of abortion are effective, safe and acceptable for termination of pregnancy of $\leq 63$ days of gestation. The combined regimen of mifepristone and misoprostol was more effective than the misoprostol alone regimen. In the combined regimen, the dosage of $800 \mu \mathrm{g}$ misoprostol was more effective than $400 \mu \mathrm{g}$. Although there were no significant differences in the dosing interval and the routes of misoprostol, the additive information on the certainty of evidence and consideration of women's satisfaction, suggest that a 24 -h interval and offering different routes of administration are effective, safe and acceptable options for medical abortion. This further highlights the fact that in many cases, demonstrating that one option does not lead to statistically significant better outcomes than the other allows for making clinical decisions based on an individual's preference. More robust studies evaluating both the different combination and misoprostol alone regimens are needed to strengthen existing evidence as well as assess patient perspectives towards a particular regimen.

\section{Supplementary information}

Supplementary information accompanies this paper at https://doi.org/10 1186/s12905-020-01003-8.

Additional file 1. Search strategies from electronic databases.

Additional file 2. Risk of bias.

Additional file $\mathbf{3}$ Table S1. Regimens for medical abortion $\leq 63$ days. Table S2. Comparison of misoprostol doses in combined regimen.

Table S3. Comparison of dosing intervals between mifepristone and misoprostol in combined regimen. Table S4. Comparison of misoprostol routes in combined mifepristone-misoprostol regimen. Table S5. Comparison of different misoprostol only regimens. Table S6. Comparison of medical and surgical management- Medical management with $800 \mu \mathrm{g}$ vaginal misoprostol compared with surgical management.

\section{Abbreviations}

Cl: Confidence Interval; GRADE: Grading of Recommendations, Assessment, Development and Evaluations; LMP: Last Menstrual Period; MeSH: Medical Subject Headings; PRISMA: Preferred Reporting Items for Systematic Reviews and Meta-Analyses; RCTs: Randomized Controlled Trials; RR: Risk Ratio; WHO: World Health Organization

\section{Acknowledgements}

The authors would like to thank Tomas Allen from World Health Organization, Geneva, Switzerland and Kavita Kothari for formulating our search strategy and organizing results of the electronic searches.

\section{Authors' contributions}

The initial review was conducted as part of the evidence synthesis for the WHO guidance on medical abortion. AL had overall responsibility of the guideline development and coordinated the work. FAA and CK conceived the idea and conducted the search, screening, data extraction and quality assessments. MIR carried out the analysis and assessed the overall quality and validity of the evidence with the GRADE (grading of recommendations assessment, development and evaluation) system. FAA and CK wrote the first draft of the manuscript. All authors participated in the revision and writing of the final manuscript 


\section{Funding}

This work was funded by the UNDP-UNFPA-UNICEF-WHO-World Bank Special Programme of Research, Development and Research Training in Human Reproduction (HRP), a cosponsored programme implemented by the World Health Organization (WHO). Extraction of the data, analysis, and composition of this manuscript was performed by WHO staff members (FAA, CK, AL) and a WHO consultant (MIR)

\section{Availability of data and materials}

The datasets supporting the conclusions of this article are included within the article and its additional files.

\section{Ethics approval and consent to participate}

Not applicable.

\section{Consent for publication}

Not applicable.

\section{Competing interests}

The authors declare that they have no competing interests.

\section{Author details}

'UNDP/UNFPA/UNICEF/WHO/World Bank Special Programme of Research, Development and Research Training in Human Reproduction (HRP) Department of Reproductive Health and Research, World Health Organization, Geneva, Switzerland. ²Department of Obstetrics \& Gynecology, Oregon Health \& Science University, Oregon, Portland, USA.

Received: 27 September 2019 Accepted: 26 June 2020

Published online: 07 July 2020

\section{References}

1. Karim SMM. Once-a-month vaginal administration of prostaglandins E2 and F2a for fertility control. Contraception. 1971:3(3):173-83.

2. Karim SMM. Use of prostaglandin $E_{2}$ in the management of missed abortion, missed labour, and hydatidiform mole. Br Med J. 1970;3(716): 196-7.

3. Karim S, Rao B, Ratnam S, Prasad R, Wong Y, llancheran A. Termination of early pregnancy (menstrual induction) with 16-phenoxy- $\omega$-tetranor PGE2 methylsulfonylamide. Contraception 1977;16(4):377-81.

4. Kahn JG, Becker BJ, Maclsaa L, Amory JK, Neuhaus J, Olkin I, Creinin MD. The efficacy of medical abortion: a meta-analysis. Contraception. 2000;61(1):29_ 40.

5. Kulier R, Kapp N, Gülmezoglu AM, Hofmeyr GJ, Cheng L, Campana A. Medical methods for first trimester abortion. Cochrane Database of Systematic Reviews 2011, Issue 11. Art. No.: CD002855. DOl: https://doi.org/ 10.1002/14651858.CD002855.pub4.

6. Blum J, Raghavan S, Dabash R, Ngoc N, Chelli H, Hajri S, Conkling K, Winikoff B. Comparison of misoprostol-only and combined mifepristone-misoprostol regimens for home-based early medical abortion in Tunisia and Vietnam. Int J Gynaecol Obstet. 2012;118(2):166-71.

7. Dahiya K, Ahuja K, Dhingra A, Duhan N, Nanda S. Efficacy and safety of mifepristone and buccal misoprostol versus buccal misoprostol alone for medical abortion. Arch Gynecol Obstet. 2012;285(4):1055-8.

8. Ngoc NT, Blum J, Raghavan S, Nga NT, Dabash R, Diop A, Winikoff B. Comparing two early medical abortion regimens: mifepristone+misoprostol vs. misoprostol alone. Contraception. 2011;83(5):410-7.

9. Chong E, Tsereteli T, Nguyen NN, Winikoff B. A randomized controlled tria of different buccal misoprostol doses in mifepristone medical abortion. Contraception. 2012;86(3):251-6.

10. von Hertzen $H$, Huong NT, Piaggio $G$, Bayalag $M$, Cabezas E, Fang AH, Gemzell-Danielsson K, Hinh ND, Mittal S, Ng EH, Chaturachinda K, Pinter B, Puscasiu L, Savardekar L, Shenoy S, Khomassuridge A, Tuyet HT, Velasco A, Peregoudov A. Misoprostol dose and route after mifepristone for early medical abortion: a randomised controlled noninferiority trial. BJOG. 2010; 117(10):1186-96.

11. Guest J, Dog PFW, Thomson MAR, Kosseim ML. Randomized controlled trial of the efficacy of same-day administration of mifepristone and misoprostol for termination of pregnancy with the standard 36 to 48 hour protocol. BJOG Int J Obstet Gynecol. 2007;114:207-15.
12. Creinin MD, Schreiber CA, Bednarek $P$, Lintu H, Wagner MS, Meyn LA. Mifepristone and misoprostol administered simultaneously versus 24 hours apart for abortion: a randomized controlled trial. Obstet Gynecol. 2007; 109(4):885-94.

13. Verma ML, Singh $U$, Singh N, Shankhwar $P$, Srivastava D. Efficacy of misoprostol administration 24 hours after mifepristone for termination of early pregnancy. Indian J Med Sci. 2011;65(12):511-7.

14. Blanchard K, Shochet T, Coyaji K, Thi Nhu Ngoc N, Winikoff B. Misoprostol alone for early abortion: an evaluation of seven potential regimens. Contraception. 2005;72(2):91-7.

15. Covidence systematic review software, Veritas Health Innovation, Melbourne, Australia. Available at www.covidence.org.

16. Higgins JPT, Green S (editors). Cochrane Handbook for Systematic Reviews of Interventions Version 5.1.0 [updated March 2011]. The Cochrane Collaboration, 2011. Available from www.handbook.cochrane.org.

17. World Bank Data Team. New country classifications by income level: 2018-2019. 2018. Available from: https://blogs.worldbank.org/opendata/ newcountry-classifications-income-level-2018-2019. Accessed 28 Oct 2018

18. Chai J, Wong CY, Ho PC. A randomized clinical trial comparing the shortterm side effects of sublingual and buccal routes of misoprostol administration for medical abortions up to 63 days' gestation. Contraception. 2013;87(4):480-5.

19. Chawdhary R, Rana A, Pradhan N. Mifepristone plus vaginal misoprostol vs vaginal misoprostol alone for medical abortion in gestation 63 days or less in Nepalese women: a quasi-randomized controlled trial. J Obstet Gynaecol Res. 2009;35(1):78-85.

20. Coyaji K, Krishna U, Ambardekar S, Bracken H, Raote V, Mandlekar A, Winikoff B. Are two doses of misoprostol after mifepristone for early abortion better than one? BJOG. 2007:114(3):271-8.

21. Dahiya K, Mann S, Nanda S. Randomized trial of oral versus sublingual misoprostol $24 \mathrm{~h}$ after mifepristone for medical abortion. Arch Gynecol Obstet. 2011;284(1):59-63.

22. El-Refaey $\mathrm{H}$, Templeton $\mathrm{A}$. Early abortion induction by a combination of mifepristone and oral misoprostol: a comparison between two dose regimens of misoprostol and their effect on blood pressure. $\mathrm{Br} J$ Obstet Gynaecol. 1994;101(9):792-6.

23. El-Refaey H, Rajasekar D, Abdalla M, Calder L, Templeton A. Induction of abortion with mifepristone (RU 486) and oral or vaginal misoprostol. N Engl J Med. 1995;332(15):983-7.

24. Fekih M, Fathallah K, Ben Regaya L, Bouguizane S, Chaieb A, Bibi M, Khairi H. Sublingual misoprostol for first trimester termination of pregnancy. Int J Gynaecol Obstet. 2010;109(1):67-70

25. Goel A, Mittal S, Taneja BK, Singal N, Attri S. Simultaneous administration of mifepristone and misoprostol for early termination of pregnancy: a randomized controlled trial. Arch Gynecol Obstet. 2011; 283(6):1409-13

26. Hamoda H, Ashok PW, Flett GM, Templeton A. A randomised controlled trial of mifepristone in combination with misoprostol administered sublingually or vaginally for medical abortion up to 13 weeks of gestation. BJOG. 2005 112(8):1102-8.

27. Jain JK, Dutton C, Harwood B, Meckstroth KR, Mishell DR Jr. A prospective randomized, double-blinded, placebo-controlled trial comparing mifepristone and vaginal misoprostol to vaginal misoprostol alone for elective termination of early pregnancy. Hum Reprod (Oxford, Engl). 2002; 17(6):1477-82

28. Middleton T, Schaff E, Fielding SL, Scahill M, Shannon C, Westheimer E, Wilkinson T, Winikoff B. Randomized trial of mifepristone and buccal or vaginal misoprostol for abortion through 56 days of last menstrual period. Contraception. 2005;72(5):328-32.

29. Prasad S, Kumar A, Divya A. Early termination of pregnancy by single-dose 800 ug misoprostol compared with surgical evacuation. Fertil Steril. 2009; 91(1):28-31

30. Raghavana S, Comendant R, Digol I, Ungureanu S, Friptu V, Bracken H, Winikoff B. Two-pill regimens of misoprostol after mifepristone medical abortion through 63 days' gestational age: a randomized controlled trial of sublingual and oral misoprostol. Contraception. 2009;79:84-90.

31. Raghavan S, Comendant R, Digol I, Ungureanu S, Dondiuc I, Turcanu S, Winikoff B. Comparison of 400 mcg buccal and 400 mcg sublingual misoprostol after mifepristone medical abortion through 63 days' LMP: a randomized controlled trial. Contraception. 2010;82(6):513-9. 
32. Schaff EA, Fielding SL, Westhoff C, Ellertson C, Eisinger SH, Stadalius LS, Fuller L. Vaginal misoprostol administered 1, 2, or 3 days after mifepristone for early medical abortion: a randomized trial. JAMA. 2000;284(15):1948-53.

33. Schaff EA, Fielding SL, Westhoff C. Randomized trial of oral versus vaginal misoprostol at one day after mifepristone for early medical abortion. Contraception. 2001;64(2):81-5.

34. Schaff EA, Fielding SL, Westhoff C. Randomized trial of oral versus vaginal misoprostol 2 days after mifepristone $200 \mathrm{mg}$ for abortion up to 63 days of pregnancy. Contraception. 2002;66(4):247-50.

35. Shannon C, Wiebe E, Jacot F, Guilbert E, Dunn S, Sheldon WR, Winikoff B. Regimens of misoprostol with mifepristone for early medical abortion: a randomised trial. BJOG. 2006;113(6):621-8.

36. Tang OS, Chan CC, Ng EH, Lee SW, Ho PC. A prospective, randomized, placebo-controlled trial on the use of mifepristone with sublingual or vaginal misoprostol for medical abortions of less than 9 weeks gestation. Hum Reprod (Oxford, Engl). 2003;18(11):2315-8.

37. Tendler R, Bornstein J, Kais M, Masri I, Odeh M. Early versus late misoprostol administration after mifepristone for medical abortion. Arch Gynecol Obstet. 2015;292(5):1051-4.

38. Verma ML, Singh U, Singh N, Sankhwar PL, Qureshi S. Efficacy of concurrent administration of mifepristone and misoprostol for termination of pregnancy. Human fertility (Cambridge, Engl). 2017;20(1):43-7.

39. von Hertzen H, Piaggio G, Huong NT, Arustamyan K, Cabezas E, Gomez M, Khomassuridze A, Shah R, Mittal S, Nair R, Erdenetungalag R, Huong TM, Vy ND, Phuong NT, Tuyet HT, Peregoudov A. Efficacy of two intervals and two routes of administration of misoprostol for termination of early pregnancy: a randomised controlled equivalence trial. Lancet (London, Engl). 2007; 369(9577):1938-46.

40. Von Hertzen H, Piaggio G, Wojdyla D, Marions L, My Huong NT, Tang OS, Fang AH, Wu SC, Kalmar L, Mittal S, Erdenetungalag R, Horga M, PretnarDarovec A, Kapamadzija A, Dickson K, Anh ND, Tai NV, Tuyet HT, Peregoudov A. Two mifepristone doses and two intervals of misoprostol administration for termination of early pregnancy: a randomised factorial controlled equivalence trial. BJOG. 2009;116(3):381-9.

41. Winikoff B, Dzuba IG, Creinin MD, Crowden WA, Goldberg AB, Gonzales J, Howe M, Moskowitz J, Prine L, Shannon CS. Two distinct oral routes of misoprostol in mifepristone medical abortion: a randomized controlled trial. Obstet Gynecol. 2008;112(6):1303-10.

\section{Publisher's Note}

Springer Nature remains neutral with regard to jurisdictional claims in published maps and institutional affiliations.

Ready to submit your research? Choose BMC and benefit from:

- fast, convenient online submission

- thorough peer review by experienced researchers in your field

- rapid publication on acceptance

- support for research data, including large and complex data types

- gold Open Access which fosters wider collaboration and increased citations

- maximum visibility for your research: over $100 \mathrm{M}$ website views per year

At $\mathrm{BMC}$, research is always in progress.

Learn more biomedcentral.com/submissions 